\title{
Toward an Open Network Business Approach
}

\author{
Valentina Ndou, Assistant Professor Laura Schina, Research Fellow - Giuseppina Passiante, Full Professor \\ Pasquale Del Vecchio, Research Fellow - Marco De Maggio, Research Fellow
}

\begin{abstract}
The aim of this paper is to propose a dynamic integrated approach, based on modularity concept and on the business ecosystem approach, that exploit different eBusiness services for SMEs under an open business network platform. The adoption of this approach enables firms to collaborate locally for delivering the best product/service to the customers as well as globally by accessing international markets, interrelate directly with the customers, create relationships and collaborate with worldwide actors. The paper will be structured as following:

We will start by offering an overview of the state of the art of eBusiness platforms among SME of food and tourism firms and then we discuss the main drawbacks that characterize them. The digital business ecosystem approach and the modularity concept will be described as the theoretical ground in which our proposed integrated model is rooted. Finally, the proposed model along with a discussion of the main value creation potentialities it might create for SMEs will be presented.
\end{abstract}

Keywords - component: Complexity; Digital Business Ecosystem; eBusiness Platforms; Modularity; Networks.

\section{INTRODUCTION}

Ith the networked world firms are recognizing the power of the Internet as a platform for creating different forms of relationships and collaborations aimed to enhance value and achieve a sustainable competitive advantage. Consequently the proliferation of a series of business models, tools, solutions, that seeks to bring Small and Medium Enterprises (SMEs) inside the digital world, is being experienced. In tourism sector SMEs are using Destination management systems (DMSs) to embark in the eBusiness, while manufacturing firms (food, textile, automotive etc.) are using digital marketplace platforms for trading their products in global markets.

These digital solutions enable firms to more efficiently buy, sell, and manage their supply chain processes on a global scale. However, different services are often only available on different platforms and the firms are not able to use all of them or a specific set of services that best fit with their strategic objectives. Thus, for example the tourism firms that use the DMS are mainly focused on Business-To-Consumer (B2C) services, while they miss in large parts the Business-ToBusiness (B2B) services.

Authors are with the Centro Cultura Innovativa d'Impresa, University of Salento, Lecce, Italy
On the other hand the manufacturing firms using digital marketplaces are mainly concerned with B2B services, missing the B2C services. Generally, sectors are represented in specific platforms without coordination and integration among them. Consequently, food firms are not reached easily by outgoing tourists in order to buy specific products tasted at destination, while tourism firms are not exploring the advantages of trading functions present in digital marketplaces that could allow them to procure the products and the materials needed for improve also their operations.

In this scenario firms are faced with the problem of deciding which solutions they need to adopt to better satisfy their customers as well as their organizational operations. In fact the usage of different platforms to benefit from different services is not affordable for SMEs in terms of costs, of human resources as well as competencies required.

In order to overpass these drawbacks, in this article we propose an integrated model that exploit different eBusiness services for SME under an open business network platform. The model we propose is a dynamic one based on modularity concept and on the business ecosystem approach.

\section{LITERATURE REVIEW}

\section{A. Electronic platforms for SMEs networking}

Firms are continuously encountered with substantial strategic discontinuities, unpredictable environment changes, and uncertainty dynamism. One of the few ways that firms, especially SMEs characterized by liabilities of smallness and newness, can successfully respond to those challenges is by increasing inter-firm cooperation or networking [5].

According to the social exchange theory no firm can survive by exclusively combining its internal resources, but it is always dependent on other firm's provision of resources, which causes a situation where this latter is exchanging resources with other firms. Accordingly, a network offer greater potential as they allow firms to access key resources from its environment, such as information, capital, goods, services that have the potential to maintain or enhance a firm's competitive advantage [14]. By building relation - specific assets, knowledge-sharing routines, and effective relational governance mechanisms into relationships, firms can leverage networks for knowledge acquisition and exploitation.

The technology enabled landscape offers new opportunities for firms networking. They create conditions for establishment of electronic networks where firms can collaborate with former competitors and potentially achieve competitive co-evolution [24]. In this vein, an important trend in various industries is the use of electronic platforms as a key enabler that allows SMEs to expand the potential benefits originating from linking electronically with suppliers, customers, and other business partners. 
In tourism sector SMEs are using DMSs to embark in the eBusiness, while manufacturing firms, are using digital marketplace platforms for trading their products in global markets. They are based on the notion of electronically connecting many buyers and suppliers to a central marketspace in order to facilitate exchanges of information, goods and services ([2]; [3]; [8]; [13]; [17]; [28]; [31]; [32]).

Digital marketplaces have become increasingly used across industries and sectors. Also, the food industry is using these platforms for exchanging their goods and services.

Kaplan and Sawhney [17] argue that there are two basic functions through which digital marketplaces can create value: aggregation and matching.

The aggregation mechanism involves bringing many buyers and sellers together under one roof, which facilitates "one-stop shopping” and thus reduces transaction costs e.g.;

The matching mechanism brings buyers and sellers together to dynamically negotiate prices on a real-time basis.

There are different services through which digital marketplaces provide the necessary capabilities for aggregation or matching. Electronic catalogues, Supplier directories, Auctions, Classified ads, Request for Quotation/Proposal/Bid (RFQ, RFP, RFB) etc.

On the other hand, small and medium tourism enterprises are using DMSs to construct a broad network of suppliers, activities and functions necessary to realize synergies in management, marketing, distribution, branding, advertising and technology planning of the entire destination. It tries to provide customers with integrated value and the service innovation of the destination. DMS, [6], [27], that supports the development of a horizontally, vertically and diagonally integrated destination by providing information, facilitating reservations and supporting transactions for an entire tourism region. These systems allow the creation of e-business models for destinations as they provide the IT infrastructure used by a destination organization for the collection, storage, manipulation and distribution of information in all its forms and for the transaction of reservations and other commercial activities' [26]. DMSs are designed to make all suppliers accessible online from everywhere, to increase the whole customer satisfaction level with an area and to promote the whole destination in global markets. By creating a broad network of suppliers and centralizing a number of functions, destination systems presents synergies in management, marketing and planning, creates economies of scale in distribution, branding, advertising and technology adaptation whereas economies of scope are facilitated through product diversification and creative product packaging [9].

These electronic platforms have promised firms a significant contribution in creating value through the decrease in transaction costs by reducing information symmetries, increasing loyalty level and enhancing transaction frequency, as well as by allowing firms to access other's resources increasing so the possibility of firms to acquire new knowledge ([1], [3], [17]).

However more than being guided toward the upgraded process of using technologies most SMEs are feeling lost in the digital world as they are being called from many types of initiatives to use Information and Communication Technologies (ICTs) for different reasons. For example the tourism structures do not know where to be part of- either to create their own website, or to enter in the catalogues of Tour operators. Making a choice among all these alternatives is difficult and choosing to be part of diverse initiatives is not affordable for them. The same situation persists for production firms such as those of food sectors which are being encountered with different solutions that propose to them either to reach international markets, or either to optimize their processes through different types of Enterprise and Resource Planning (ERP) systems. So, having also in mind the drawbacks that characterize SMEs as well as the competencies and costs required for implementation of single digital solutions they are having difficulties on determining which solutions to adopt first, in which marketplaces to enter, how to integrate theirs elves with international markets.

In order for firms to deal with the complexity of environment and technology they need to evolve toward more dynamic networking solutions which exploits the dynamic interaction of several players in order to produce systemic results in terms of innovation and economic development [22]. The dynamic networking challenges organizations to develop sound strategies to mobilize their networks in such a way that they become part of the right temporary alignments and/or start up the right temporary alignments [33].

\section{TOWARD AN OPEN BUSINESS NETWORK}

\section{A. Principles of the open business network approach}

The open business network is based on the principles of digital business ecosystem and modularity.

A Digital Business Ecosystem is defined as the joint between the Moore's "Business Ecosystem" definition (1996) ${ }^{1}$ and the use of ICTs for managing socio-economic aspects [22]; in other words, the term refers to a "digital environment, populated by digital species which could be: software components, applications, services, knowledge, business models, training experiences, contractual frameworks, laws, and so on". [22] According to this interpretation a Digital Business Ecosystem can be break down into three main layers (Fig. 1) [23]:

- The "Business" layer: represented by an economic community built on the interactions between organizations and individuals. The main purpose of this community, made by heterogeneous categories of players, is to confer an added value to customers ${ }^{2}$, producing goods and services. In addition, the balance

1 Moore (1996) wrote: “An economic community supported by a foundation of interacting organizations and individuals - the organisms of the business world. This economic community produces goods and services of value to customers, who are themselves members of the ecosystem. The member organizations also include suppliers, lead producers, competitors, and other stakeholders. Over time, they co-evolve their capabilities and roles, and tend to align themselves with the directions set by one or more central companies. Those companies holding leadership roles may change over time, but the function of ecosystem leader is valued by the community because it enables members to move toward shared visions to align their investments and to find mutually supportive roles.

2 According to the Moore's definition, customers are themselves members of the ecosystem. 
between the cooperation and the competition in a so dynamic environment is equivalent to the wealth of the same ecosystem.

- The "Ecosystem" layer: represented by the biological metaphor, that give evidence of the interdependence of all players involved. Living within this environment, enables the co-evolution of the capabilities and roles of all actors.

- The "Digital" layer: represented by the technical infrastructure, based on Peer-To-Peer (P2P) technologies, able to transport, find and connect multiple services and information through Internet links, enabling networked transactions and the usage of a distributed digital environment.

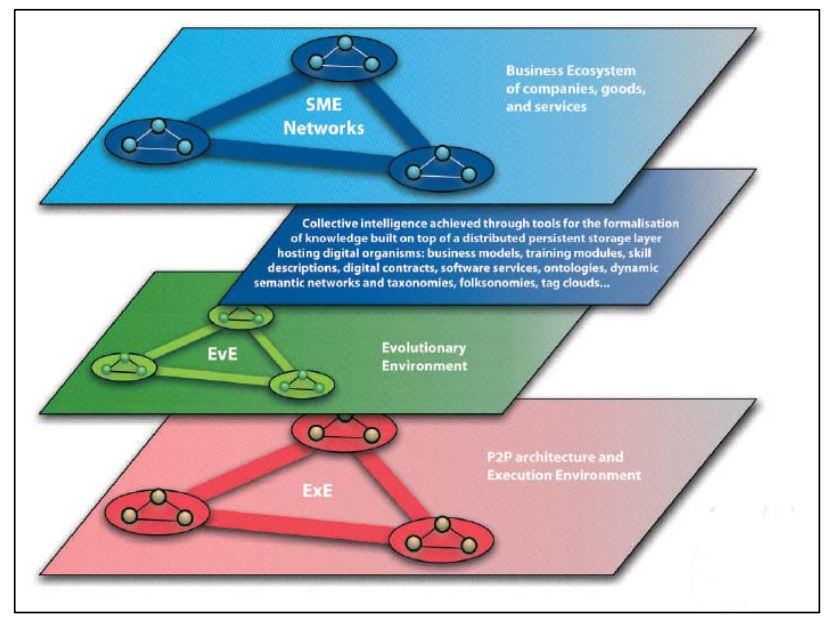

Fig. 1 The stack view of the Digital Business Ecosystem. Source: Digital Business Ecosystem Book 2007

In the digital business ecosystems, the business services and the software components are supported by a pervasive software environment, which shows an evolutionary and self organizing behavior [23]. In this context, firms, used to slowly change their way of conduct a business, have to replace a more fluid, amorphous and usually transitory structure focused on way of collaboration and cooperation as: alliances, partnerships and so on. Moreover, small organizations, facing the major difficulties to the transition from traditional practices to eBusiness activities, should afford this challenge developing networked organization so to cooperate and share information and best practices.

Comparing to the biological metaphor, business organizations are equivalent to the organisms, and at the same way can act, collaborating each other, to create more complex structures ${ }^{3}[23]$.

Thus, business is conducted through a rapidly formed network with anyone, anywhere, anytime regardless of different computer systems and business processes [33].

The modularity principle can be used as a managing approach and can have different meanings with regards to the

3 In this definition, a business ecosystem includes, apart from the owners and the main stakeholders, different players, as: government agencies, regulators, associations, standard bodies, representatives and host communities, direct and indirect competitors with which can also collaborate. specific context. A complex system, for example a product design, an organization structure or a biological system, consists of parts that interact and have some degree of interdependence [29].

The tasks within a multidivisional firm or dynamic network of organizations are intentionally designed to require low levels of coordination so that they can be carried out by an organizational structure of quasi-independent entities functioning as a loosely coupled system .The concept of organizations as loosely coupled systems is widely used and diversely understood, according to Orton \& Weick [25].

Sanchez \& Mahoney [29] further elaborate on this and define modularity as "a special form of design which intentionally creates a high degree of independence or a loosecoupling between component designs by standardizing component interface specifications". Therefore, from now on we consider loose coupling between components to be an important feature of a modular design.

Almost all systems are, to some degree, modular according to Schilling [30], and many systems try to evolve towards modularity. Schilling argues that modularity at its most abstract level refers to the degree to which a system's components may be separated and recombined. The primary action of increasing modularity is to enable heterogeneous configurations, thus it increases the flexibility of a system.

In broadest terms, modularity is an approach for organizing efficiently the design and production of complex products and processes [4]. Complex tasks are decomposed into simpler elements so that they can be managed independently and yet operate together as a whole. A motivation behind decomposition of a complex system into more manageable parts is to gain flexibility and cost savings through economies of scale. In addition to cost advantages, modularity also has positive impacts on a firm's specialization [20], product variety [29]; [30], new product development flexibility [4]; [7]; [15]; [30], and the number of compatible suppliers [19];[20].

From a system's perspective, modularity can be perceived as a continuum outlining the degree to which a system's components can be decomposed and recombined as well as the tightness of coupling between components and the degree to which the rules of the system architecture enable (or prohibit) the mixing-and-matching of components [30]. Modularity permits components to be produced separately, or loosely coupled [25]; [29], and used interchangeably in different configurations without compromising system integrity [10]; [11]. The idea of modularity in a business network is to standardize the components of the system (a product or process) in such a way that they can be separated and recombined fairly easy [16] and can exploit the possibility to realize business products and services in a way that they can be self contained. This makes modularity a powerful approach to organize complex products [34] as well as to make complexity manageable by making possible to run experiments at the level of modules, rather than the entire artifact, and in parallel [4].

Hoogeweegen, Teunissen and Vervest [16] propose a modular network design approach to support the realization of modularly designed processes for production and delivery of products and services. According to this approach customer requirements are modelled in modular service elements and 
satisfiers are modelled in capability elements. A service element describes a specific feature of a total product and/or service range. By mixing and matching specific service elements, a customer is able to specify exactly his or her requirements. A capability element refers to a skill, resource or capability to produce a specific service element. By linking the service elements to the capability elements, only those capability elements are activated which are actually requested by the customer by selecting a specific set of service elements.

In a dynamic market with many customized requests for products, each customer order consists of a different set of service elements, therefore a different set of capability elements is needed, which results in a different set of organizations which together form a temporary alignment to fulfill this specific customer order.

\section{THE OPEN NETWORK APPROACH PROPOSAL}

The open business network model proposed is articulated on three layers, grouped in a common network (Fig. 2):

- The aggregation of industry, government, research institutions and other stakeholders under a common basic network infrastructure, in order to perform the local development on a global scale. The involvement of different types of actors is required for building a strong network of stakeholders aiming to achieve common goals. The benefits for the SMEs can be the access to information and technologies dynamically aggregated in order to exchange knowledge, solve specific requirements, and find valuable partnerships. Through collaboration these entities can create communities of interest that can leverage strengths, solve common problems, innovate and build upon existing efforts. In our case the actors referred to the business domain constituted by the Agrifood sector, the Tourism and Cultural Heritage Domains and the Public Institution as public player within an environment populated by different species. The decision to consider these three domains is followed to the analysis of the resources available within the area of interest, represented by the Southern Italy that have the major possibility to reach high levels of performance.

- The applicability of this approach in a specific local level requires the central and strong participation of a key unit, that as has been argued by Kogut [18] and many scholars of strategic management literature, they serve as a source of leadership and order to define the boundaries of the networks strategic activities. Thus a second layer is needed consisting on a central local unit that will serve as a hub or a facilitator and its function is very crucial for realizing critical mass of the platform as well as for promoting, integrating and upgrading the SMEs of a specific locality. In our approach this layer is represented by the Intelligent Territorial Centre (ICT). The role of this central local unit, is fundamental, in order to help SMEs in searching for and deciding on who create profitable collaborations, because of e.g. their probable lack of valuable information sources and financial resources, in order to scanning and monitoring the complex environment. The ICT works in an automated way according to static and dynamic functions provided entering into the platform:

- The static functions are related to the capability to just synchronize the work of network e.g. by intermediating some services among buyers and sellers (such as the bid aggregation). This also include the capability of this actor to be a marketmaker which bring buyers and sellers together and facilitate transactions by providing the platform and deciding which processes, rules and provide new added e-services.

- The dynamic functions are much more complex and refer to the capabilities to sense, seize and monitor the competitive landscape to identify new opportunities and to reorganize the value chain. Of particular interest for this actor will be the competitiveness of local network firms as such they must be able to cure the territorial SME interests. They will work toward bringing together different stakeholders' interests, lead them toward cooperation instead of competition and pool resources towards developing territorial SMEs.

Among the main capabilities this unit needs to perform are:

- The coordination of all territorial SMEs' activities, promoting them and providing leadership, in order to expand the beneficial community impacts in the area.

- The establishment of a shared vision among the members of the network through the brand power, trust rating systems.

- The retrieve, store, combination and integration of the skills and knowledge that flows and accumulates in the network to be able to deliver new customized products and services. As Grant [12] argues knowledge integration in an inherent organizational capability.

- The development of skills and capabilities of members through the organizations of training as well as through a good strategy of network knowledge management.

- The last layer is represented by the technological infrastructure in which are comprised the range of eservices directly provided by the platform. These services can be composed in a modular way and adapted to the users' requirements, taking into account both the possible needs of a firm that already uses technologies and of a firm with a lower rate of ICTs' adoption. These services are not exclusive either for a tourism firm or a food firm. They can be used by both of them. For example tourism firms can use the Classified Ads services to put hotel rooms for sale at best price. Also the bid aggregation services could be used by tourism firms especially from small hotels or bed and breakfast that could not reach the tour operator or large distributors as result of costs and other limitations decided by these intermediaries (room quantities). They could be integrated together in order 
to satisfy the requirements of the tour operators (in terms of room quantities, as well as costs).

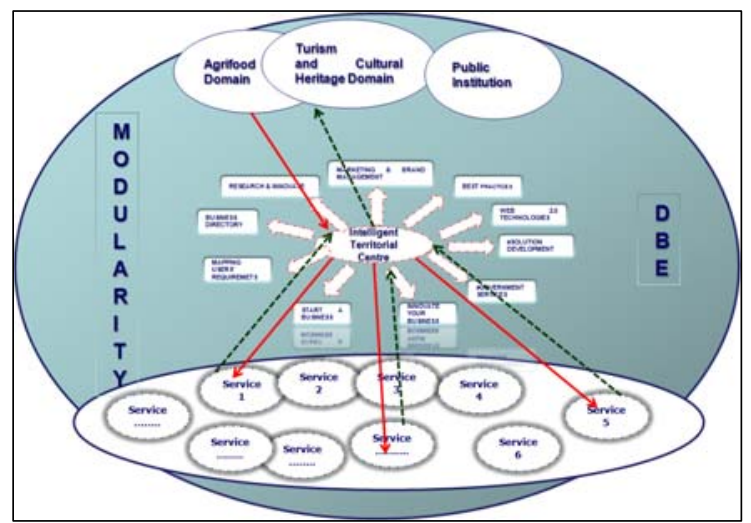

Fig. 2 Open Business Network Platform

This approach is of support for SMEs' competitiveness in the complex environments. Through the adoption of this approach they are able to collaborate locally and globally. On local level firms of different sectors can come together, interrelate and collaborate for delivering the best product/service to the customers. While on global level through the coordination of central local unit and networking platforms they are able to access international markets, interrelate directly with the customers, create relationships and collaborate with worldwide actors. The common technology also is an advantage as firms do not anymore need to install different hardware and software applications modules for realizing products, they simply need to plug and play different modular applications.

\section{CONCLUSIONS}

The main purpose of this paper was to provide an efficient and simple solution able to allow SMEs the access in the digital world. In order to reach this goal, we have suggested a platform based on the modularity and business ecosystem approach.

The "Open Business network Approach", aims to ensure the opportunity to evolve according to the requirements of a wide range of users within different industries and this is thanks to the way with which the services are implemented and provided.

We underline as the main feature of the platform is its capability to start and consolidate the collaboration among firms both locally and globally located. In this way, grows the possibility to create a network of relationships and gain a competitive position in a complex environment.

The initial stage of adoption will be addressed to give the firms the awareness on the benefits about this new way of doing business and then try to identify specific patterns for different requirements. The process of adoption have to be understood as a continuous process so our interest will be dedicated to design these changing paths.

The work gives also evidence of the importance of an intermediate actor able to lead the development of different patterns of innovation and support the shift from business to ebusiness operations within different contexts. Particularly important is its capability to transform individual activities into a common base of experiences for all participants, contributing to create valuable networks of expertise.

Future research is oriented to investigate a further range of services able to reinforce the presence of SMEs in the growing eBusiness community. This imply a deep analysis of the different degree of adoption of ICTs, distinguishing e.g. among the basic, medium and high levels, according to the background of any firms that will be involved. Particularly attention will be dedicated to develop user friendly interfaces useful to facilitate the adoption of the platform because of the importance to have simple application within the context of SMEs.

\section{REFERENCES}

[1] Amit R. and Zott C., "Value creation in e-business", Strategic Management Journal, 2001.

[2] Bakos, J. Y., “A strategic analysis of electronic marketplaces”, MIS Quarterly, vol. 15, no 3, pp. 295-310, 1991.

[3] Bakos, J.Y., "The emerging role of electronic marketplaces on the Internet”, Common ACM, vol. 41, no. 8, pp. 35-42, 1998.

[4] Baldwin CY, Clark KB., "Managing in an age of modularity", in Managing in the Modular Age, Garud R , Kumaraswamy A , Langlois RN (eds). Blackwell: Oxford; 149-161, 2003.

[5] Baum J.A.C., Oliver C., "Institutional linkages and organizational mortality”, Administrative Science Quarterly, vol. 36, pp. 187-218, 1991.

[6] Buhalis, D., "Information and telecommunications technologies as a strategic tool for small and medium tourism enterprises in the contemporary business environment”, in Seaton, A., et al (Eds), Tourism-The State of the Art: The Strathclyde Symposium, Wiley and Sons, England, pp.254-275, 1994.

[7] Christensen, C.M. and Rosenbloom, R., "Explaining the attacker's advantage: technological paradigms, organisational dynamics and the value network”, Research Policy 24, 233-257, 1995.

[8] Dai, Q., \& Kauffman, R. J., "Business models for internet-based B2B electronic markets”, International Journal of Electronic Commerce, vol. 6, no 4, pp. 41-72, 2002a.

[9] Dargan, L., Prosser, G., "Towards an e-business strategy for SMEs in the irish tourism industry”, 31st European Small Business Seminar Dublin, September 2001.

[10] Garud R, Kumaraswamy A., "Changing competitive dynamics in network industries: an exploration of Sun Microsystems' open-systems strategy”, Strategic Management Journal 14(5): 351-369, 1993.

[11] Garud R, Kumaraswamy A, Langlois RN., "Managing in the modular age: architectures, network, and organizations", in Managing in the Modular Age, Garud R , Kumaraswamy A , Langlois RN (eds). Blackwell: Oxford, U.K.; 1-11, 2003.

[12] Grant, R. M., “Toward a knowledge-based theory of the firm”, Strategic Management Journal, 17 (Winter Special Issue): 109-122, 1996.

[13] Grieger, M., "Electronic marketplaces: a literature review and a call for supply chain management research", European Journal of Operational Research, vol. 144, pp 280-294, 2003.

[14] Gulati, R., "Network location and learning: the influence of network resources and firm capabilities on alliance formation", Strategic Management Journal, 20: 397-420, 1999.

[15] Henderson, R.M., Clark, K.B., “Architectural innovation: the reconfiguration of existing product technologies and the failure of established firms”, Administrative Science Quarterly, 35: 9- 30, 1990.

[16] Hoogeweegen, M., Teunissen, W.J., Vervest, P.H.M., and Wagenaar, R., "Modular network design: using information and communications technology to allocate production tasks in a virtual organization", Decision Sciences 30, 4 (Fall 1999), 1073-1103, 1999.

[17] Kaplan, S. and Sawhney, M., "E-hubs: the new B2B marketplaces", Harvard Business Review, vol. 3, pp. 97-103, 2000.

[18] Kogut, B., "The network as knowledge: generative rules and the emergence of structure”, Strategic Management Journal 21, pp. 405425, 2000. 
[19] Langlois RN, Robertson PL., "Networks and innovation in a modular system: lessons from the microcomputer and stereo component industries”, Research Policy 21(4): 297-313, 1992.

[20] Langlois RN, Robertson PL., "Commentary. In managing in the modular age”, Garud R , Kumaraswamy A , Langlois RN (eds). Blackwell: Oxford, UK; 101-113, 2003.

[21] Moore J., "Death of competition; leadership and strategy in the age of business ecosystems ”, HarperBusiness, reprint edition, May 1997.

[22] Nachira, F., "Towards a network of digital business ecosystems fostering the local development”, Bruxelles, Discussion paper, 2002.

[23] Nachira F., Dini P., Nicolai A., "A network of digital business ecosystem for Europe: roots, processes and perspectives”, European Commission, Information Society and Media, pp.1-18, 2007.

[24] Ordanini, A., \& Pol, A., "Informediation and competitive advantage in D2B digital marketplaces”, European Management Journal, vol. 19, no 3, pp. 276-285, 2001.

[25] Orton, J.D. \& K.E. Weick, "Loosely coupled systems: a reconceptualization”, Academy of Management Review 15(2), 203-223, 1990.

[26] Pollock, A. and Benjamin L., "Shifting sands: the tourism ecosystem", in Transformation DesticorpLtd., 2001.

[27] Poon, S., \& Swatman, P., "An exploratory study of small business internet commerce issues”, Information and Management, vol. 35, pp. 9 18, 1999.

[28] Raisch, W. D., “The e-marketplace: strategies for success in B2B ecommerce”, New York: McGraw-Hill, 2001.

[29] Sanchez, R, and Mahoney T.J., "Modularity, flexibility, and knowledge management in product and organization design," Strategic Management Journal, Vol. 17 (winter special issue), 63-76, 1996.

[30] Schilling, M.A., "Toward a general modular systems theory and its application to interfirm product modularity", Academy of Management Review, Vol. 25 No.2, pp.312-34, 2000.

[31] Segev, A., Gebauer, J., \& Fäber, F., "Internet-based electronic markets", EM - International Journal of Electronic Markets, vol. 9, no 3, pp. 138146, 1999.

[32] Turban, E., King, D., Lee, J., Warkentin, M., \& Chung, H. M., "Electronic commerce - a managerial perspective", Upper Saddle River, New Jersey: Prentice Hall, 2002.

[33] Van Heck, E., Vervetst, P., "Smart business networks”, Communications of the ACM Volume 50, Issue 6, 2007.

[34] Venkatraman, N., Henderson, J., "Real strategies for virtual organizing”, Sloan Management Review 40(1), pp. 33-48Weick, K. E. (1976). Education systems as loosely coupled systems. Administrative Science Quarterly, 21.1_19, 1998. 